\title{
Culture Perfusion Schedules Influence the Metabolic Activity and Granulocyte- Macrophage Colony-Stimulating Factor Production Rates of Human Bone Marrow Stromal Cells
}

\author{
JERRY CALDWELL, BERNHARD O. PALSSON, BETTY LOCEY, AND \\ STEPHEN G. EMERSON* \\ Departments of Chemical Engineering (J.C., B.O.P.) and Internal Medicine (B.L., S.C.E), \\ University of Michigan, Ann Arbor, Michigan 48109
}

\begin{abstract}
The metabolic function and GM-CSF production rates of adherent human bone marrow stromal cells were investigated as functions of medium and serum feeding rates. A range of medium exchange schedules was studied, ranging from a typical Dexter culture protocol of one weekly medium exchange to a full media exchange daily, which more closely approximates what bone marrow cells experience in situ. Glucose consumption was found to be significantly higher at full daily exchange rate than at any other exchange schedule examined. However, the lactate yield on glucose was a constant, at $1.8 \mathrm{~mol} / \mathrm{mol}$, under all conditions considered. Differential serum vs. medium exchange experiment showed that both serum supply and medium nutrients were responsible for the altered behavior at high exchange rates. Glutamine consumption was found to be insignificant under all culture conditions examined. A change in exchange schedule from $50 \%$ daily medium exchange to full daily medium exchange after 14 days of culture was found to result in a transient production of GM-CSF and a change in metabolic behavior to resemble that of cultures which had full daily exchange from day one. These results suggest that both stromal cell metabolism and GM-CSF production are sensitive to medium exchange schedules. Taken together, the data presented indicate that attempts to model the function of human bone marrow in vitro may be well served by beginning with medium exchange schedules that more closely mimic the in vivo physiologic state of bone marrow.
\end{abstract}

Hematopoiesis occurs within highly dense cellular niches within the bone marrow in the adult and in similar niches within the fetal yolk sac and liver. Within these niches, stem cell differentiation is regulated, in part, through interactions with local mesenchymal cells or stromal cells. Studies of hematopoiesis in in vitro liquid marrow cultures have identified fibroblasts and endothelial cells within adherent layers as central cellular stromal elements (Bentley and Foidart, 1980; Mendelow et al., 1980; Lanotte et al., 1981; Patt et al., 1982; Allen and Dexter, 1983). These cells both provide sites of attachment for developing hematopoietic cells (Bentley, 1981; Coulombel et al., 1983; Slovick et al., 1984; Gordon et al., 1985; Matsuoka and Tavassoli, 1989; Verfaillie et al., 1990) and can be induced to secrete hematopoietic growth factors which stimulate progenitor cell proliferation and differentiation (Bagby, et al., 1986; Delwiche et al., 1985; Zucali et al., 1986; Munker et al., 1986; Zucali et al., 1987; Thorens et al., 1987; Kaushansky et al., 1988). These hematopoietic growth factors include granulocyte colony stimulating factor (G-CSF), granulocyte- macrophage colony stimulating factor (GM-CSF), and interleukin six (IL-6).

Cultures of human bone marrow cells on such adherent layers in vitro, however, have been largely disappointing. Unlike related cultures from other species, such as mouse (Dexter and Lajtha, 1984; Dexter et al., 1977) and tree shrew (Moore et al., 1979), human liquid marrow cultures fail to produce significant numbers of either nonadherent hematopoietic precursor cells or clonogenic progenitor cells for over six to eight weeks, although 20-week cultures have been reported (Toogood et al., 1980; Hocking and Golde, 1980; Gartner and Kaplan, 1980; Greenberg et al., 1981). Moreover, nonadherent and progenitor cell production typically de-

Received November 12, 1990; accepted February 7, 1991.

*To whom reprint requests/correspondence should be addressed at Department of Internal Medicine, Division of Hematology and Oncology, Medical Science Research Building 1 Room 5510B, $1150 \mathrm{~W}$. Medical Center Drive, University of Michigan, Ann Arbor, MI 48109. 
cline throughout even the short lifetime of these cultures, so that it is not clear that stem cell survival or proliferation is supported at all by these cultures. Further, when studied in isolation, unstimulated bone marrow stromal cells secrete little if any detectable hematopoietic growth factors (HGFs) (Nimer et al., 1989). While many explanations for failure to detect HGFs in uninduced stromal cell cultures have been suggested, the null hypothesis, which combines the failure to detect HGFs and the relative failure of human liquid marrow cultures, would be that the culture systems used in vitro do not provide the full range of hematopoietic supportive function of adherent bone marrow stromal cells in vivo.

We have, therefore, begun to explore the physiologic regulation of stromal cell function, focusing on differences between the local stem cell environment in vivo and the environment of standard liquid in vitro marrow cultures. The clearest difference is that the rate of delivery of plasma proteins and nutrients to bone marrow, and the rate of removal of cellular metabolic wastes, is far higher in vivo than in in vitro cultures. In vivo perfusion rates of marrow are reported to be on the order of $0.1 \mathrm{ml} / \mathrm{cc} / \mathrm{min}$ (Martiat et al., 1987) and if one assumes an in vivo cell density of $5 \times 10^{8}$ cells $/ \mathrm{ml}$, then this perfusion rate corresponds to using $0.23 \mathrm{ml}$ serum per $10^{6}$ cells per day. This perfusion rate is thus similar to full daily exchange of tissue culture medium containing $20 \%$ serum in cultures that have densities of $10^{6}$ cells $/ \mathrm{ml}$, which are typical cell densities used in liquid bone marrow cultures. However, the standard exchange schedules for liquid bone marrow cultures call for a single weekly exchange. These exchange rates are thus at 7-fold lower than what the cells experience in vivo. For liquid culture cell densities that are higher than $10^{6} \mathrm{cell} / \mathrm{s} / \mathrm{ml}$, the departure from in vivo conditions is even greater.

In the present study, we therfore asked whether stromal cell physiology is sensitive to serum nutrient and protein perfusion rates. Using fundamental measurements of cell metabolic physiology, the results indicate that perfusion rate is an important factor in determining stromal cell metabolism, and its manipulation will undoubtedly have direct impact on attempts to model bone marrow function in vitro.

\section{MATERIALS AND METHODS Bone marrow cells}

Bone marrow from normal adult volunteers was aspirated into preservative-free heparin under a protocol approved by the University of Michigan Human Investigations Committee. Mononuclear cells were isolated by centrifugation over Ficoll-Hypaque SG 1.077 and were washed three times prior to initiation of cell cultures.

\section{Establishment and maintenance of adherent layers}

Adherent layers were established by culturing at $10^{6}$ cells/ml normal human bone marrow mononuclear cells in $75 \mathrm{~cm}^{2}$ tissue culture flasks in Iscoves Modified Dulbecco's Medium (IMDM) supplemented with $20 \%$ fetal calf serum (FCS), $1 \% \mathrm{P} / \mathrm{S}$. Nonadherent cells were removed after overnight incubation and discarded. Dur- ing the subsequent establishment of the adherent layers, medium was exchanged twice weekly. When the cultures approached confluence, the adherent cells were trypsinized and replated to remove any residual myeloid cells. Adherent monolayers used in these studies had been passaged twice and had reached confluence at the initiation of the studies. All cultures were maintained at $37^{\circ} \mathrm{C}$ and $5 \% \mathrm{CO}_{2}$ in a humidified incubator.

\section{Medium exchange rates and monitoring of the cultures}

Stromal cell growth curve. Replicate 6-well tissue culture dishes were inoculated with passaged stroma cells at a density of $1 \times 10^{4}$ cells $/ \mathrm{cm}^{2}$. These cultures were then maintained for one week, with a single $50 \%$ medium exchange mid-week before starting the experimental protocol. Triplicate cultures (3 wells) were sacrificed to determine the starting cell density. Replicate cultures were maintained under one of two medium exchange schedules, either $100 \%$ exchange daily or $50 \%$ twice per week. At weekly or biweekly intervals, duplicate cultures (wells) from each medium exchange protocol were trypsinized and the adherent cell density determined by hemocytometer.

Glucose and glutamine metabolism. Parallel cultures of passaged adherent bone marrow cells were maintained on each of four schedules: 1) one-half of the medium exchanged twice weekly ( 1 weekly exchange equivalent); 2) all of the medium exchanged twice weekly (2 exhanges weekly); 3 ) one-half the medium exchanged daily (3.5 exchanges weekly); and 4) all of the medium exchanged daily (7 exchanges weekly). Aliquots of each culture were assayed for glucose, lactate, glutamine, and ammonia concentrations.

On day 14 the exchange schedules for cultures 2 ) and 3 ) were changed in the following way: 2) was changed from $2 /$ week to the traditional $1 /$ week schedule, whereas the 3.5/week was changed to the rapid 7/week exchange rate. Culture 2) was terminated on day 20 , as its behavior was not significantly altered by the shift in exchange schedule and its metabolic behavior was similar to culture 1).

Differential medium and serum exchange. Replicate 6-well tissue culture dishes were seeded with passaged stroma cells then cultivated to visual confluence $\left(3.5-4.0 \times 10^{4} \mathrm{cells} / \mathrm{cm}^{2}\right)$. One set of replicate cultures (3 plates) received $100 \%$ medium exchanged daily with medium containing $20 \%, 10 \%$, or $5 \%$ fetal calf serum, respectively. An identical set of cultures received $100 \%$ medium exchange every other day. Aliquots of the removed medium at each exchange were analyzed for glucose concentration. Glucose consumption was determined by subtracting the concentration in the spent medium from the concentration in the fresh added either the day before or two days earlier. At day 14 and 21 into the medium exchange protocol, duplicate wells from each set were trypsinized for cell density determination.

\section{Metabolic measurements}

Glucose and lactate. Aliquots of removed supernatants were diluted 1:3 with deionized water, and then glucose and lactate concentrations were measured us- 
ing a YSI Model 2000 Analyzer (Yellow Springs Instrument Co. . Dilution reduced the concentration of glucose and lactate to within the ranges of greatest sensitivities of the YSI analyzer $(<100 \mathrm{mM}$ glucose, $<20 \mathrm{mM}$ lactate).

Glutamine and ammonia. Medium ammonia concentration was measured directly using an ammonium ion specific electrode (Orion Model 95-12) and a Beckman Phi $45 \mathrm{pH} / \mathrm{mV}$ meter. Ammonia concentrations were determined from the $\mathrm{mV}$ readings by interpolation from $\mathrm{mV} / \mathrm{NH}_{4}^{+}$concentration standard curves performed in parallel. Glutamine concentration was determined by repeating the ammonia measurement following enzymatic conversion of all the medium glutamine to ammonia, using glutaminase. For conversion of glutamine to ammonia, $50 \mu \mathrm{l}$ of culture supernatant was incubated with $40 \mu \mathrm{l} 0.1 \mathrm{mM} \mathrm{NaAc}, \mathrm{pH} 4.9$, and $10 \mu \mathrm{l}$ of $10 \mathrm{U} / \mathrm{ml}$ glutaminase (grade II $E$. Coli glutaminase, Sigma)/0.005M NaAc, $\mathrm{pH} 6.0$ solution for 15 minutes at $37^{\circ} \mathrm{C}$. Following this incubation the $\mathrm{pH}$ was adjusted to 7.0 adjusted with a $\mathrm{pH}$ stabilizing solution, and $\mathrm{mV}$ were measured as above. To be certain that all of the glutamine had been converted to ammonia, a second standard curve was constructed utilizing known concentrations of glutamine as the starting material.

\section{GM-CSF assay}

GM-CSF concentrations were determined by ELISA. Ninety-six-well microtiter plates were coated with monoclonal mouse-anti human GM-CSF antibody (Genzyme, Boston, MA) overnight at $4^{\circ} \mathrm{C}$. Following extensive washing and blocking with PBS/Tween 20 buffer, samples or varying quantities of purified recombinant GM-CSF (Genetics Institute, Boston, MA) were added to each well and incubated for 1 hour at $37^{\circ} \mathrm{C}$. After washing the wells, rabbit anti-GM-CSF (Genzyme) was then added for 1 hour at $37^{\circ} \mathrm{C}$, the wells washed and biotinylated goat anti-rabbit Ig added for 45 minutes at $37^{\circ} \mathrm{C}$. Finally, avidin/peroxidase conjugate was added for 40 minutes at $37^{\circ} \mathrm{C}$, and $o$-phenylene diamine dichloride (Tago) was added until the most concentrated standards were a deep yellow color, at which time $1 \mathrm{M} \mathrm{H}_{2} \mathrm{SO}_{4}$ was added to each well to stop the reactions. Absorbances were read in a ELISA plate reader, and GM-CSF concentrations were determined by interpolation to the standard curves developed in parallel. Each sample was analyzed in triplicate, and all values were precise $\pm 5 \%$, with the limit of detection of the assay of $0.01 \mathrm{ng} / \mathrm{ml}$.

\section{RESULTS \\ Glycolytic metabolism in cultured adherent marrow cells}

To characterize the dynamics of substrate consumption and metabolite build-up in adherent stromal cells, we began by measuring the primary indices of glycolytic activity-glucose consumption and lactate production. Confluent monolayers of adherent stromal cells were cultured in parallel T-flasks under four media exchange schedules: one-half the medium changed twice weekly ( $1 /$ week, the traditional schedule employed in human and murine bone marrow Dexter cultures), all the medium changed twice weekly ( $2 /$ week), one-half the medium exchanged daily (3.5/ week), and complete medium exchange daily ( $7 /$ week). Glucose and lactate concentrations were measured from each withdrawn sample. From these data, metabolite fluxes and functional respiratory coefficients were directly derived.

Glucose concentration in the samples from the cultures treated under traditional Dexter exchange conditions (1/week) rapidly fell and reached a steady state of approximately $10 \mathrm{mM}$ within two weeks (Fig. 1). During the steady state plateau, glucose was consumed at a rate of approximately $1.5 \mathrm{mM} / \mathrm{day}$ (Fig. 2A). Adherent cells cultured under the $2 /$ week and 3.5/week medium exchange schedules consumed glucose at slightly higher rates of about $2-3 \mathrm{mM} /$ day (Fig. 2C). On the other hand, the 7/week exchange cultures glucose consumption increased over the first 20 days of culture to reach a glucose consumption rates of $6-8 \mathrm{mM} /$ day. Cultures that were maintained on the $2 /$ week and $3.5 /$ week exchange schedule were shifted to $1 /$ week and 7/week, respectively, 14 days into culture (Fig. 2C). Within one week after the shift, in both cultures, glucose comsumption adjusted to levels observed in the cultures maintained on the 1 /week and 7/week schedules throughout, suggesting that metabolic behavior is reversible.

The lactate concentration in cultures of adherent cells treated under traditional Dexter exchange conditions rose rapidly and achieved steady state concentrations of about 22-24 mM (Fig. 1B), reflecting lactate production of approximately $2.4 \mathrm{mM} /$ day (Fig. 2B). Throughout the culture period, the molar ratio of glucose consumed to lactate produced was steady at 1.8 (Fig. 3), indicating that glucose metabolism was largely but not completely anaerobic. Adherent cells cultured under the 2/week and 3.5/week exchange schedules produced more lactate at a rate of about $4-5 \mathrm{mM} /$ day (Fig. 2D). As with glucose consumption, the $7 /$ week cultures generated progressively more lactate, eventually reaching a production rate of about $12-14 \mathrm{mM} /$ day lactate. The lactate yield coefficient under each of the exchange schedules was essentially constant throughout each individual culture, and quite similar between cultures (Fig. 3). Thus, more rapid medium exchange approximating in vivo physiologic stromal perfusion resulted in approximately 5 -fold increase in glucose metabolism, without shifting the lactate yield coefficient of the cells.

We next asked whether this significantly increased rate of cellular metabolism was related to the cell proliferation rates and total cell density. Cell proliferation in the cultures maintained on the $7 /$ week schedule had a doubling time of about two and a half days over the first five days, after which time the rate slowed considerably, compared with very little cell proliferation in the cultures exchanged once per week over the same period (Fig. 4).

\section{Glutamine metabolism}

Glutamine is a major source of carbon and metabolic energy for many cultured cell lines, including fibroblastoid cells (McKeehan 1986). We thus followed both glutamine consumption and ammonia production in bone marrow stromal cell cultures. Both the glutamine 

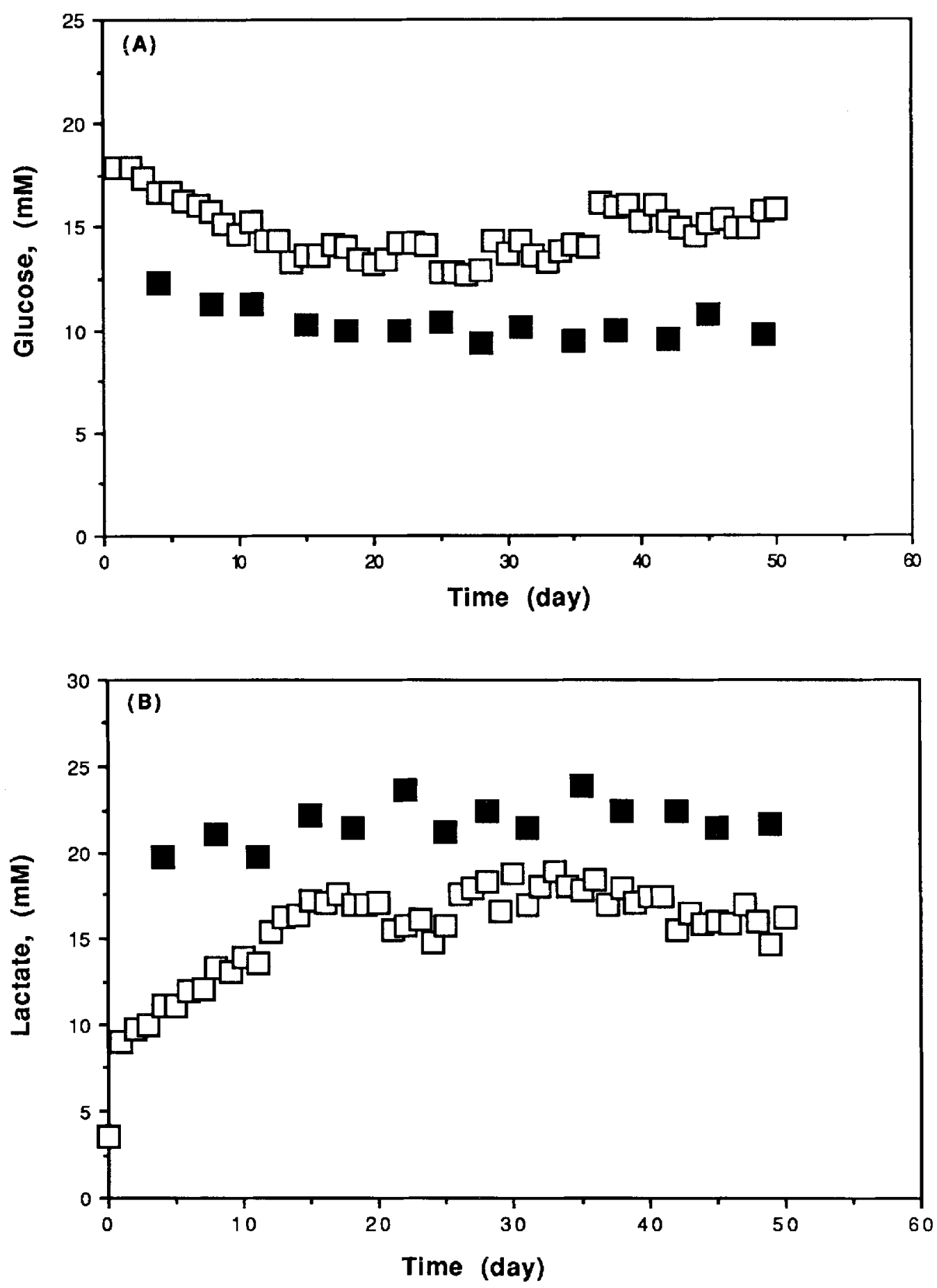

Fig. 1. The (A) glucose and (B) lactate concentration over time in cultures that had medium exchanged daily, 7/week (open squares); and exchanged weekly, 1 /week (closed squares). Each time medium was exchanged, an aliquot of the removed medium was assayed for glucose and lactate concentrations as described in Materials and Methods.

and ammonia production rates varied between $0.25-0.5$ $\mathrm{mM}$ /day for each of the cultures. These rates, however, can be attributed simply to the spontaneous decomposition of glutamine in the medium. The first order rate constant for the chemical decomposition of glutamine at $37^{\circ} \mathrm{C}$ in IMDM at $\mathrm{pH}$ of 7.2 has been reported to be $0.002 / \mathrm{hr}$ (Ozturk and Palsson, 1990). Thus, approximately $5 \%$ of the glutamine is lost over 24 hours due to chemical decomposition. The initial glutamine concentration in the medium used was about $4 \mathrm{mM}$, and thus 

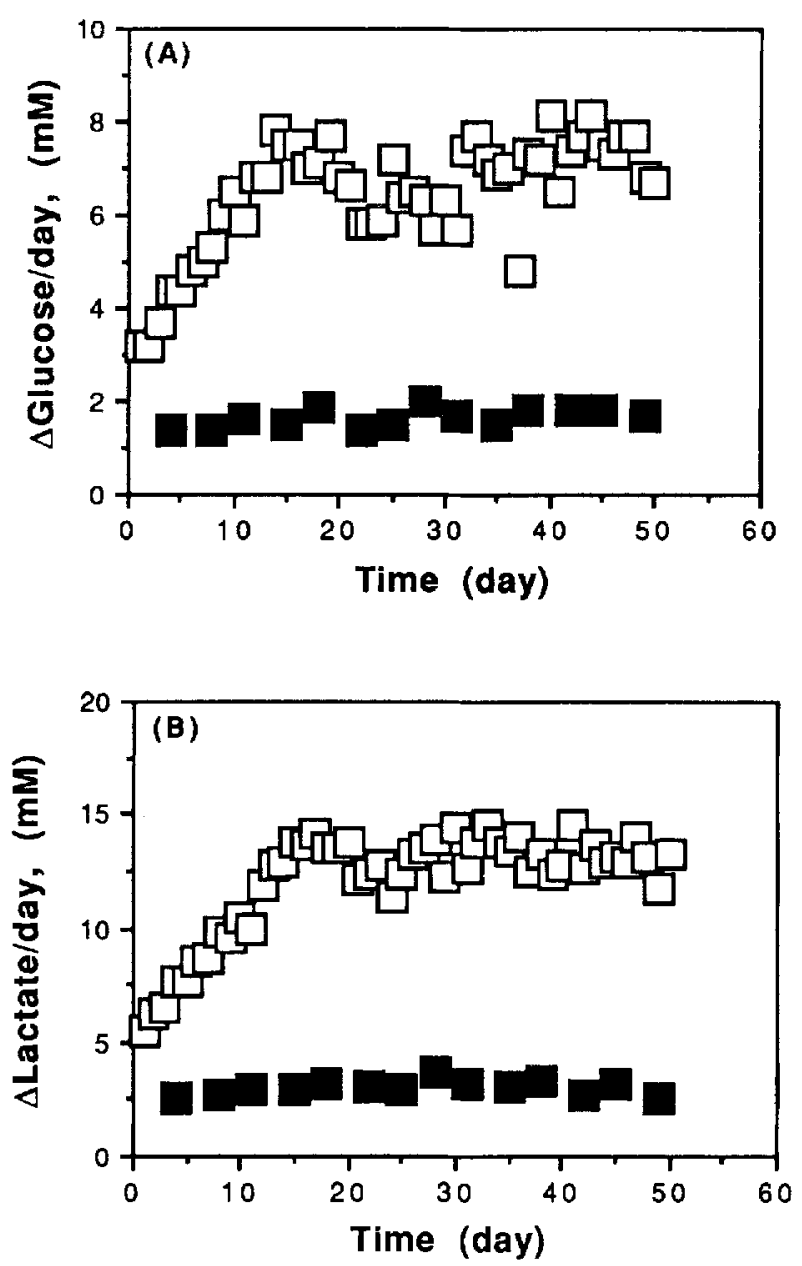

Fig. 2. Glucase consumption and lactate production rates as a function of the medium perfusion rate. Medium in duplicate $10 \mathrm{ml}$ cultures was exchanged on each of the following schedules: daily $10 \mathrm{~m}$ complete exchange (7/week, open square), daily $5 \mathrm{ml}$ medium exchange (3.5/week, open circle), biweekly complete $10 \mathrm{ml}$ medium exchange ( 2 'week, closed circle), and biweekly $5 \mathrm{ml}$ medium exchange (1/week, closed square). On day 14 of culture, the cultures exchanged on the 3.5/week and 2/week schedules were shifted to $7 /$ week (open circle), and $1 /$ week (closed circle), respectively. The cultures that were shifted to $1 /$ week were terminated on day 21 . At each medium

$0.2 \mathrm{mM}$ are lost to chemical decomposition alone during the first 24 hours. This loss is close to the measured disappearance of glutamine and thus there does not appear to be significant uptake and utilization of glutamine by normal human bone marrow stromal cells.

\section{Differential medium and serum exchange rates}

Even in the traditional, low exchange rate cultures, the glucose concentration was always at least $10 \mathrm{mM}$ and glutamine concentration over $3 \mathrm{mM}$. Therefore, the decreased glucose consumption rates of these cultures could not be explained by substrate deprivation per se. The alternate explanations were that (1) toxic metabolites or lowered $\mathrm{pH}$ in the infrequently exchanged cultures directly inhibited the adherent cell metabo-
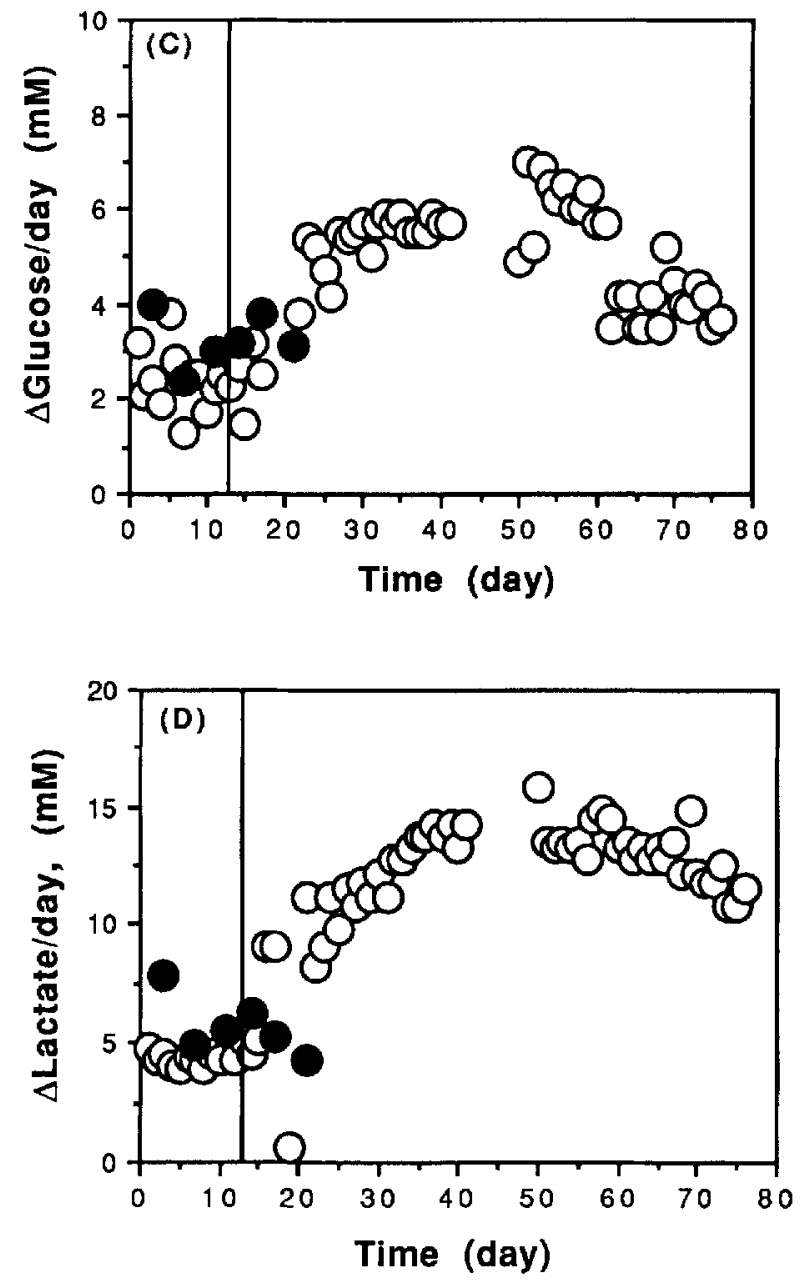

exchange an aliquot of spent medium was assayed for glucose and lactate concentration. Consumption and production was determined by subtracting the concentration measured in the spent medium from the value measured in fresh medium. Panel A: Daily glucose consumption for cultures exchanged 1/week and 7/week. Panel B: Daily lactate production in cultures exchanged 1/week and 7/week. Panel C: Daily glucose consumption for cultures exchanged 3.5/week and $2 /$ week and shifted on day 14 to $7 /$ week and 1/week, respectively. Panel D: Daily lactate production for cultures exchanged 3.5/week and $2 /$ week and shifted on day 14 to $7 /$ week and $1 /$ week, respectively.

lism, or (2) the supply of a medium nutrient or serum component other than glucose was rate limiting for adherent cell glucose metabolism, or (3) the supply of a key serum component was rate limiting.

To discriminate between these two, glucose consumption was compared under medium exchange schedules where the exchange rates of serum was kept a constant while the medium was exchanged at different rates. For instance, we compared culture exchanged daily with $10 \%$ serum with culture exchanged with $20 \%$ serum every other day. In these parallel cultures, we compared cell proliferation and specific glucose uptake with both the serum flux and medium (base) flux. In these studies, the degree of cell proliferation was directly proportional to total serum flux. Specific glucose uptake rates, however, were not linearly corre- 


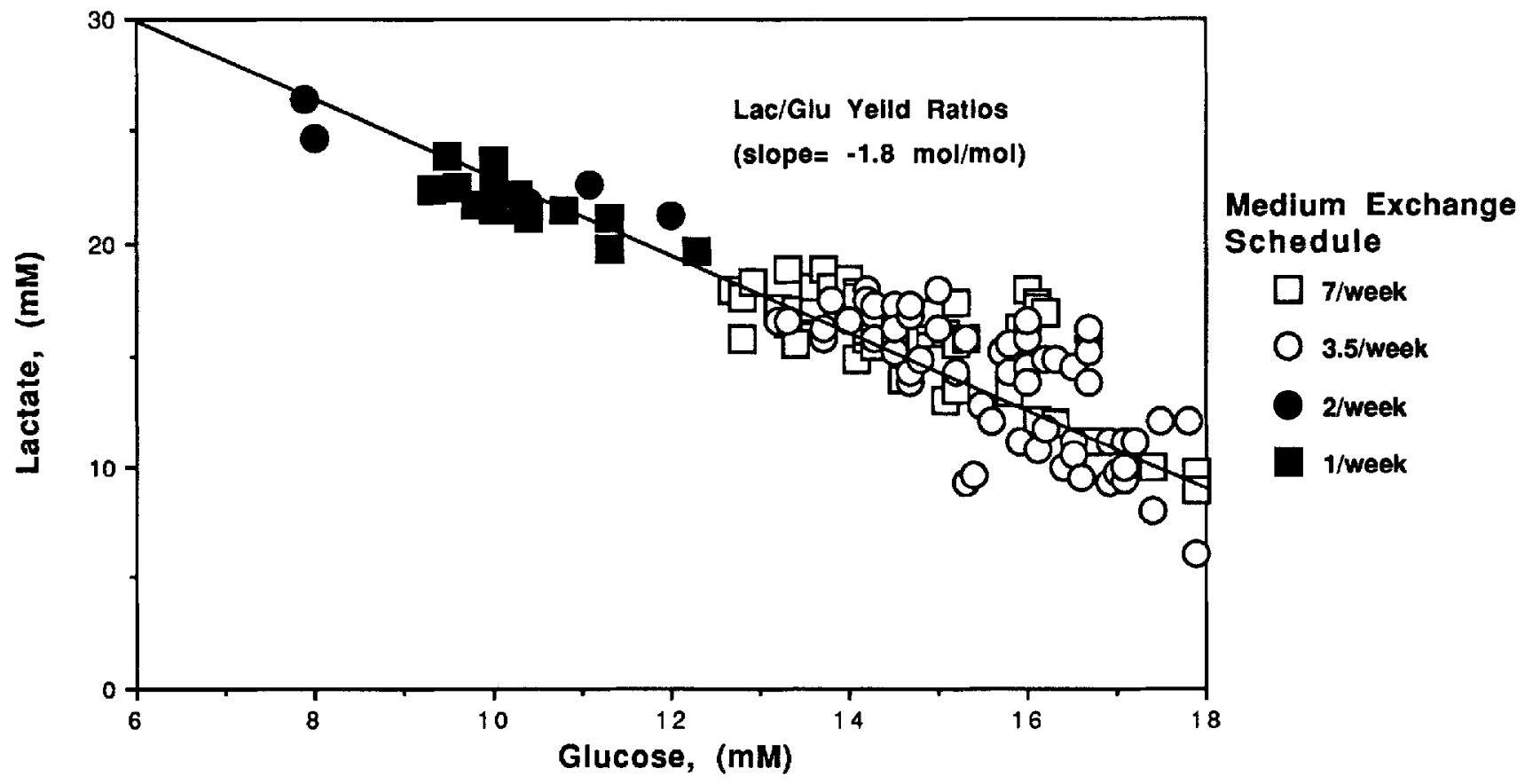

Fig. 3. Daily lactate consumption as a function of the daily glucose consumption rate. Symbols are described in Figure 2 . The molar ratio of lactate production to glucose consumption was approximately $1.8 \mathrm{~mol} / \mathrm{mol}$ for all four culture conditions.

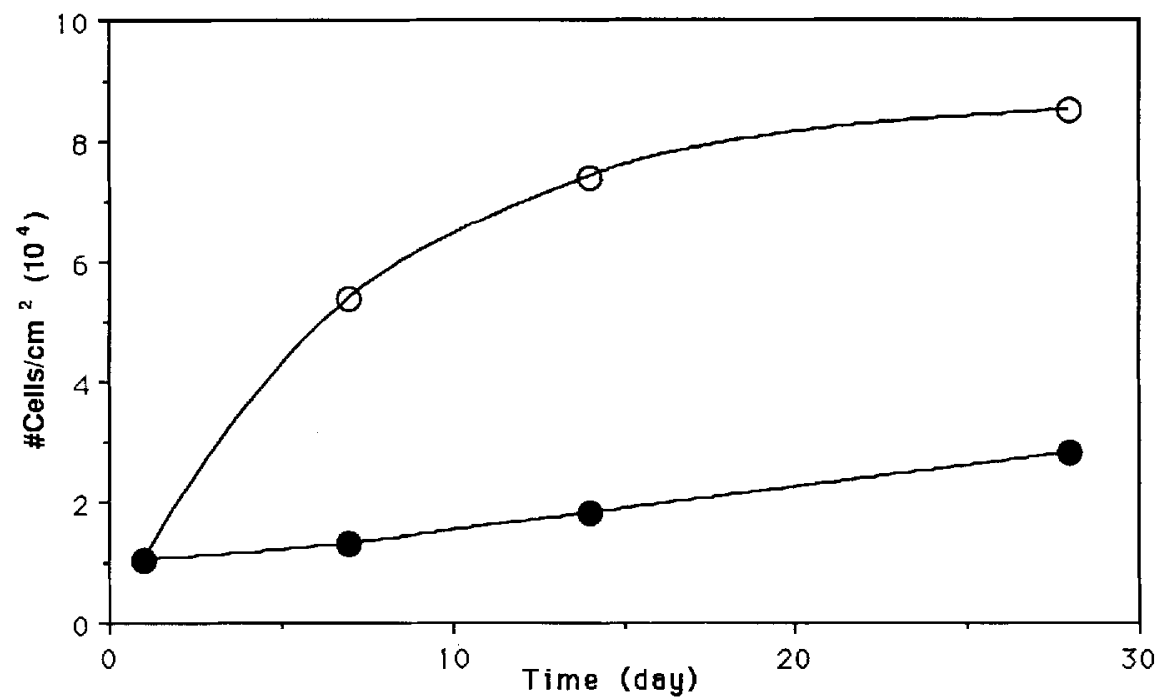

Fig. 4. Stromal cell growth as a function of medium exchange schedule. Replicate sub-confluent cultures were established in 6-well tissue culture dishes and stromal cell proliferation was measured over a four-week period under either $100 \%$ medium exchange daily (open circle) or $50 \%$ exchange biweekly (closed circle). At the times indicated triplicate cultures from each of the exchange schedules were trypsinized and the cell density determined.

lated with serum flux, but instead with medium flux (Fig. 5). Therefore, it appeared that it is the supply of a nutrient(s) or a stimulant(s) in the serum which regulate $^{5}$ adherent cell growth, and the supply of a medium component(s) (or the removal of a toxic metabolite) that regulate cell metabolism. Thus, the in- creased metabolism measured in the rapidly exchanged cultures was not simply due to increased cell numbers, but was caused by decreased metabolism per cell as well. Of note, in traditional Dexter cultures these medium and serum constituents are supplied at far lower than physiologic rates. 

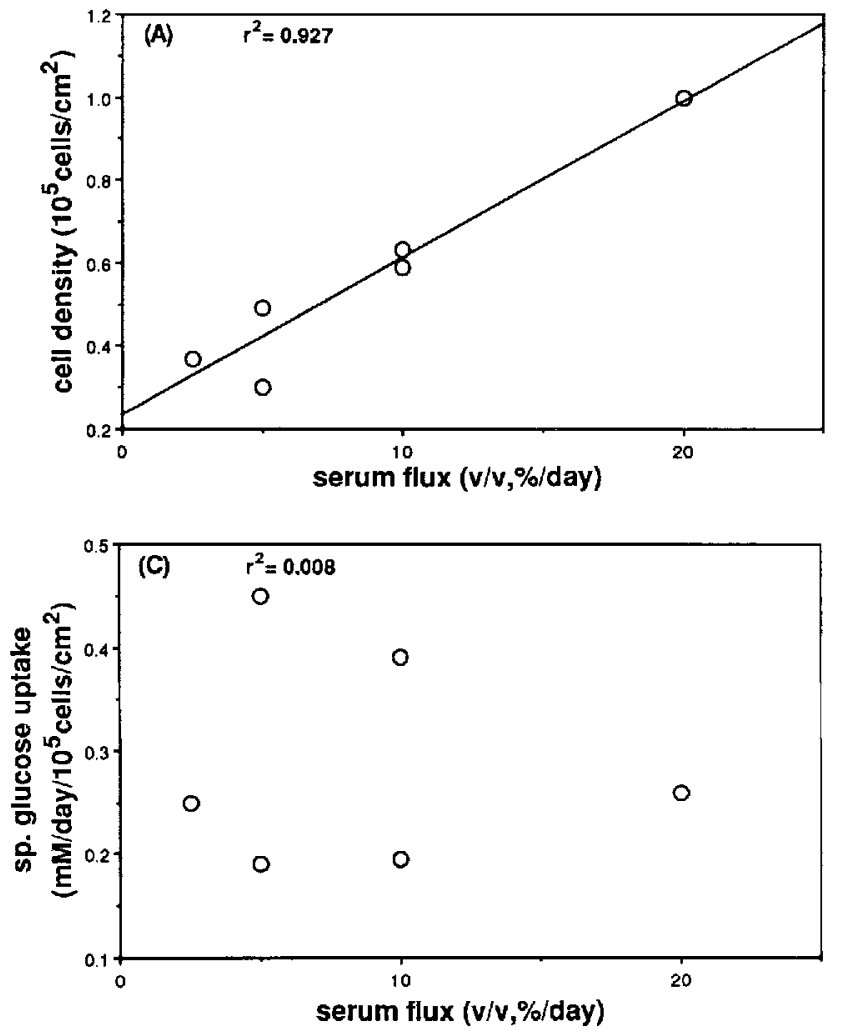

Fig. 5. Cell densities and specific glucose consumption rates as a function of medium (base) and serum flux. One set of replicate cultures (3 plates) received $100 \%$ medium exchanged daily with medium containing $20 \%, 10 \%$, or $5 \%$ fetal calf serum, respectively. An identical set of cultures received $100 \%$ medium exchange every other day. Aliquots of the removed medium at each exchange were analyzed for glucose concentration and consumption as described in Materials and Methods. At day 14 and 21 into the medium exchange protocol duplicate wells from each set were trypsinized for cell density deter-

\section{Granulocy te-macrophage colony stimulating factor (GM-CSF) secretion}

Experiments from many laboratories, using fibroblasts and endothelial cells from many sources, have documented that these cells can be induced to secrete lymphokines, including GM-CSF, by several mediators of inflammation including interleukin-1(IL-1) and tumor necrosis factor-alpha (TNF- $\alpha$ ). These cells, which are the predominant cells in the bone marrow stromal microenvironment, are therefore thought to be the in situ source of essential hematopoietic growth factors. However, in these culture and assay systems, no lymphokine secretion is detected by unstimulated cells. We therefore asked whether or not GM-CSF might be detected in bone marrow stromal cells cultured under any of the four medium exchange schedules employed for the metabolic studies. Utilizing an ELISA assay with a detection limit of $0.01 \mathrm{ng} / \mathrm{ml}$, we were unable to detect GM-CSF secreted under any of the four cultures maintained at a stable rate. However, in cultures in which the rate of medium exchange was increased from 3.5 to 7 exchanges per week, GM-CSF secretion was detectable for two weeks, reflecting GM-CSF secretion
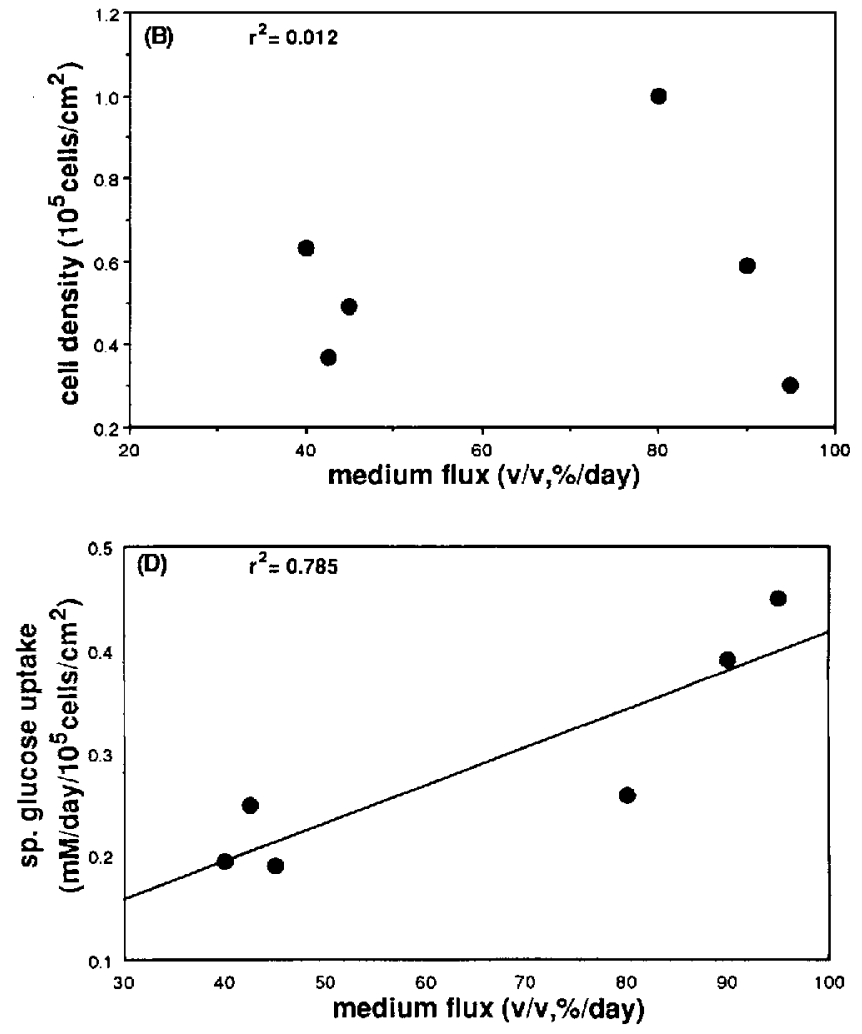

mination. Note that cultures that received $100 \%$ medium exchange every other day received an equivalent serum content to that of the cultures exchanged daily with medium containing one-half the serum concentration, e.g. daily exchanges with medium containing $10 \%$ scrum was equivalent to every other day exchanges with medium containing $20 \%$ serum. A: cell density as a function of serum flux. B: cell density as a function of medium flux. C: specific glucose uptake as a function of serum flux. D: specific glucose uptake as a function of medium flux.

rates of $0.013-0.22 \mathrm{ng} / \mathrm{ml} / \mathrm{day}$ (Fig. 6). Thus, GM-CSF secretion appeared to be transiently induced by the increase in medium and serum exchange.

\section{DISCUSSION}

The function of the bone marrow microenvironment in supporting hematopoiesis is critical, as perhaps is best illustrated by the defect in W/Wv mice whose stem cells are normal but whose microenvironment only supports deficient hematopoietic differentiation (McCulloch et al., 1964). Attempts to determine the identity and function of the key cellular elements in the microenvironment have met with some success, but have been hampered by the inability of in vitro models to accurately mimic functioning hematopoiesis in vivo. In the present study, we have explored this issue by asking whether or not closer approximations of stromal perfusion dynamics to the in vivo situation would influence the metabolism of adherent bone marrow cells. We began with this approach because the normal in vivo perfusion of bone marrow is approximately 0.1 $\mathrm{ml} / \mathrm{cc} / \mathrm{min}$. Estimating that the concentration of bone marrow cells within the marrow cavity is approxi- 


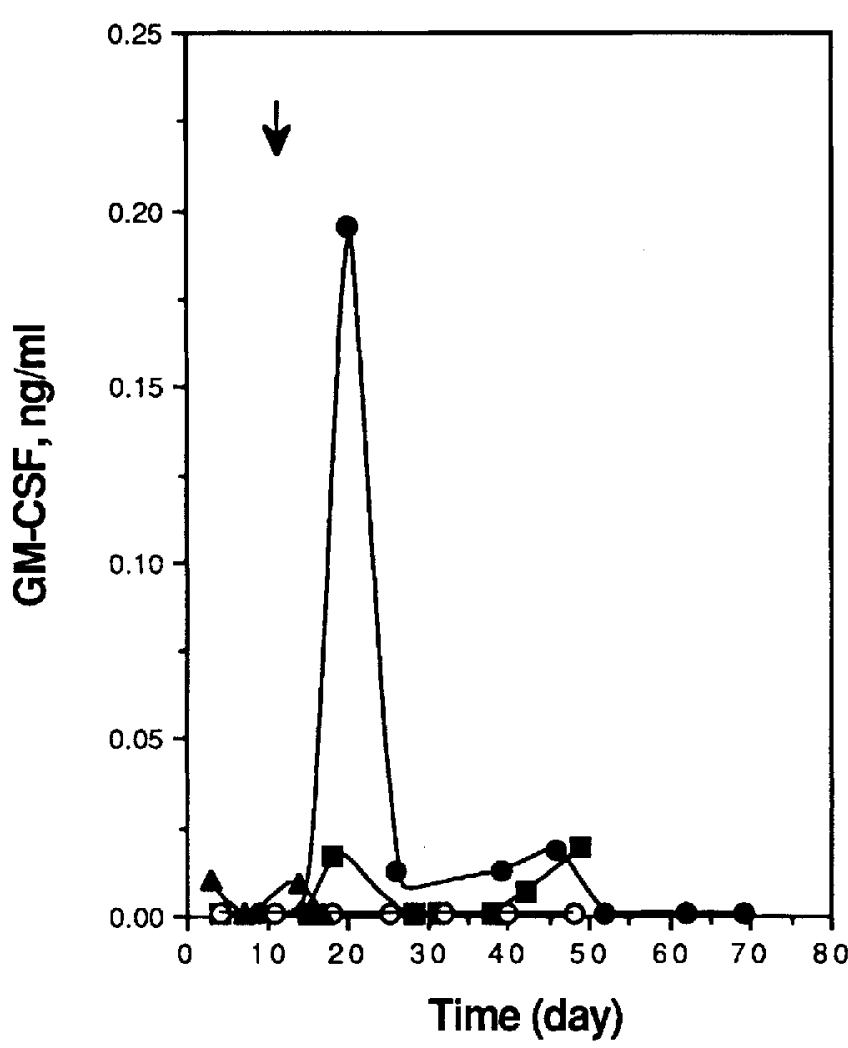

Fig. 6. GM-CSF production as a function of the medium exchange schedule. Aliquots from medium removed from cultures exchanged at $7 /$ week (open circle), 3.5/week (closed circle), 2/week (closed triangle), or $1 /$ week (closed square) during each week of culture were assayed for GM-CSF by ELISA. The cultures that were started on the 3.5/week (closed circle) medium exchange schedule were shifted to $7 /$ week on day 14 (arrow).

mately $5 \times 10^{8}$ per cc, the perfusion rate then is equivalent to approximately a daily media change of $20 \%$ serum medium in cultures which have $10^{6}$ cells per $\mathrm{ml}$. This rate very closely approximates the perfusion achieved in standard liquid bone marrow cultures established at $1-2 \times 10^{6}$ cells per ml, if the medium were completely exchanged every $12-24$ hours.

The results obtained from these measurements lead directly to several conclusions. First, metabolic, growth and hematopoietic growth factor production rates of adherent bone marrow stromal cells are sensitive to the medium exchange protocols employed in the cultures. This result is important, because (1) protocols employed among different bone marrow culture laboratories vary significantly, (2) all exchange schedules are far from the rate of plasma exposure to bone marrow cells in vivo, and (3) all are submaximally supportive of stromal cell metabolism. It is interesting that some investigators have examined the effects of medium exchange rates on marrow culture function, but the most rapid exchange rates examined were equivalent to two full exchanges per week (Gartner and Kaplan, 1980; Greenberg et al., 1981). Thus, according to our results the stimulatory effects of more rapid perfusion would not have been expected.

The next conclusion from the data is that stromal cell metabolism in vitro is largely anaerobic, and the respiratory quotient is not altered by more rapid medium exhange. These data suggest that the anaerobic metabolism observed is not an artifact of infrequently exchange the cultures with poor oxygen delivery, since more rapid exchange of fresh medium would have been expected to have resulted in more oxidative metabolism and a lower lactate yield coefficient. These results are interesting in light of several studies suggesting that both erythroid and myeloid differentiation are actually favored under relatively hypoxic conditions, equivalent to ambient $\mathrm{pO}_{2}$ of approximately $40 \mathrm{~mm} \mathrm{Hg}$ (Bradley et al., 1978; Rich and Kubanek, 1982; Ishikawa and Ito, 1988).

The hypometabolic effects of low perfusion frequency appeared to be relatively reversible, at least following a 14-day exposure, once more rapid perfusion was established. Thus, the experiments did not uncover any permanent alteration from the suboptimal exchange rates over a period of 14 days. If longer exposure to a low perfusion state were to result in irreversible loss of stromal cell metabolic activity, however, this might in part explain the poor function of Dexter stromal cells following only $6-8$ weeks culture.

Experiments in which both serum concentration and medium exchange rates were varied suggested that the supply of some non-serum medium component was responsible for the increased metabolic activity observed, possibly an amino acid other than glutamine. Thus, at least as observed in isolated stromal cells per $s e$, there is no evidence that slow perfusion results in suppression of, or damage to, the stroma due to toxic metabolites. If that were the case, one would have expected to observe decreased metabolism in high serum cultures exchanged infrequently. In fact, comparison of the rates of glucose consumption and lactate production under these conditions showed more decrease related to decreased exchange frequency per se. These results suggests that some rapidly consumed, as yet undetermined, component in the non-serum medium is responsible for the stimulation of stromal cell metabolism observed in these cultures.

Finally, upshifting of the medium exchange rates resulted in the detection of GM-CSF secretion into the culture supernatants by otherwise unstimulated stromal cells (Fig. 6). These cells had been exposed to no known inflammatory mediators. Previous failues to detect CSF secretion in a soluble form by unstimulated stromal cells may, therefore, have been caused, in part, by the culture conditons imposed on those experiments. The present data raise the possibility that bone marrow stromal cells in vivo may actually secrete GM-CSF under basal conditions, due to the high plasma flux experienced within the bone marrow. In this regard, the finding that GM-CSF secretion into the culture rate supernatant was only transiently triggered by the shift in medium exchange rate suggests that pulsatile delivery of plasma components may be critical to the native regulation of cytokine secretion in vivo. The precise role of rapid and/or pulsatile supply of such medium and plasma components requires further detailed studies. Similarly, the role of increased medium and serum delivery to GM-CSF deposition directly into the extracellular matrix might be itself investigated. 
Transient protein expression has been reported in a number of systems after mitogenic stimulation. In particular, proteins whose synthesis are driven by promoters containing elements responsive to mitogenic and inflammatory stimuli, such as serum, IL-1, and LPS, have demonstrated this type of behavior. In these systems, induction of mRNA synthesis have been shown to be coupled with message stability via a postranscriptional mechanism involving a highly conserved 3' untranslated region (UTR) (Shaw and $\mathrm{Ka}$ men, 1986). The GM-CSF gene contain both of these regulatory elements (Shaw and Kamen, 1986; Kaushanshy, 1989; Shannon et al., 1988; Koeffler et al., 1988; Thorens et al., 1987), and, thus, might explain the transient production of GM-CSF by stroma cells stimulated via an increase in medium perfusion.

In summary, we have investigated the metabolic function of adherent bone marrow stromal cells as a function of medium and serum exchange rates, comparing a range of schedules between traditional Dexter culture rates and that which may more closely approximate that seen by bone marrow cells in situ. The results suggest that stromal cell metabolism, and perhaps GM-CSF production as well, is extremely sensitive to such rates. Taken together, the data indicate that attempts to model the function of human bone marrow in vitro may be well served by beginning with perfusion schedules that closely mimic the physiologic state of the bone marrow microenvironment in vivo.

\section{ACKNOWLEDGMENTS}

This work was supported by a grant from the National Science Foundation Emerging Technology Initiative and by a research contract from Ann Arbor Stromal, Inc. We would like to thank Ms. Kelly Hardesty for her technical assistance.

\section{LITERATURE CITED}

Allen, T.D., and Dexter, T.M. (1983) Long term bone marrow cultures: An ultrastructural review. Scanning Electron Microsc., 4:18511866.

Bagby, G.C., Dinarello, C.A., Wallace, P., Wagner, C., Hefeneider, S., and McCall, E. (1986) Interleukin 1 stimulates granulocyte-macrophage colony-stimulating activity release by vascular endothelial cells. J. Clin. Invest., 78:1316-1323.

Bentley, S.A., and Foidart, J.M (1980) Some properties of marrowderived adherent cells in tissue culture. Blood, 56:1006-1012.

Bentley, S.A. (1981). Close range cell: Cell interaction required for stem cell maintenance in continuous bone marrow culture. Exp. Hematol, 9:308-312.

Bradley, T.R., Hodgson, G.S., and Rosendaal, M. (1978) The effect of oxygen tension on haemopoietic and fibroblast cell proliferation in vitro. J. Cell. Physiol., 97:517-522.

Coulombel, L., Eaves, A.L., and Eaves, C.J. (1983) Enzymatic treatment of long-term human marrow cultures reveals the preferential location of primitive hematopoietic progenitors in the adherent layer. Blood, 62:291-297.

Delwiche, F., Raines, E., Powell, J., Ross, R., and Adamson, J. (1985) Platelet-derived growth factor enhances in vitro erythropoiesis via stimulation of mesenchymal cells. J. Clin. Invest., 76:137-142.

Dexter, T.M. and Lajtha, L.G. (1974) Proliferation of hematopoietic stem cells in vitro. Br. J. Haematol., 28:525-530.

Dexter, T.M., Allen, T.D., and Lajtha, L.G. (1977) Conditions the proliferation of hematopoietic stem cells in vitro. J. Cell. Physiol., 91:335-344.

Gartner, S., and Kaplan, H.S. (1980) Long-term culture of human bone marrow cells. Proc. Natl. Acad. Sci. U.S.A., 77:4756-4759.

Gordon, M.Y., Hibbin, J.A., Dowding, C., Gordon-Smith, EC., and
Goldman, J.M. (1985) Separation of human blast progenitors from granulocytic, erythroid, megakaryocytic, and mixed colony-forming cells by "panning" on cultured marrow-derived stroma layers. Exp. Hematol., 13:937-940.

Greenberg.'H.M., Newburger, P.E., Parker, L.M., and Greenberger, J.S. (1981) Generation of physiological normal human peripheral blood granulocytes in continuous bone marrow cultures. Blood, 58:118-129.

Hocking, W.G., and Golde, D.W. (1980) Long-term human bone marrow cultures. Blood, 56:118-129.

Ishikawa, Y., and Ito, T. (1988) Kinetics of hematopoietic stem cells in a hypoxic culture. Eur. J. Haematol., 40:126-129.

Kaushansky, K., Broudy, V.C., Harlan, J.M., and Adamson, J.W. (1988) Tumor necrosis factor-alpha and tumor necrosis factor-beta (lymphotoxin) stimulate the production of granulocyte-macrophage colony-stimulating factor, macrophage colony-stimulating factor, and IL-1 in vivo. J. Immunol., 141(10):3410-3415.

Kaushansky, K. (1989) Control of granulocyte-macrophage colonystimulating factor production in normal endothelial cells by positive and negative regulatory elements. J. Immunol., 143(8):2525-2529.

Koeffler, H.P., Gasson, J. and Tobler, A. (1988) Transcriptional modulation of myloid colony-stimulating factor expression by tumor necrosis factor and other agents. Mol. Cell. Biol., 8:3432-3438.

Lanotte, M., Allen, T. and Dexter, T.M. (1981) Histochemical and ultrastructural characterization of a cell line from human bonemarrow stroma. J. Cell Sci., 50:281-297.

Martiat, Ph., Ferrant, A., Cogneau, M., Bol, A., Rodhain, J., Michaux, J.L., and Sokal, G. (1987) Assessment of bone marrow blood flow using positron emission tomography: No relationship with bone cellularity. Br. J. Haematol., 66:307-310.

Matsuoka, T. and Tavassoli, M. (1989) Purification and partial characterization of membrane-homing receptors in two closed murine hematopoietic progenitor cell lines. J. Biol. Chem., 264:2019320198.

McCulloch, E., Siminovitch, L., and Till, J. (1964) Spleen-colony formation in anemic mice of genotype W/Wv. Science, 144:844-845.

McKeehan, W.L. (1986) Glutaminolysis in animal cells. In: Carbohydrate Metabolism in Cultured Cells. M.J. Morgan. Plenum Press, New York. pp. 111-151.

Mendelow, B., Grobicki, D., Hunt, De La, Katz, J., and Metz, J. (1980) Characterization of bone marrow stroma cells in suspension and monolayer cultures. Br. J. Haematol., 46:15-22.

Moore, M.A.S., Sheridan, A.P.C., Allen, T.D., and Dexter, T.M. (1979) Prolonged hematopoiesis in a primate bone marrow culture system: Characteristics of stem cell production and hematopoietic microenvironment. Blood, 54(4):775-793.

Munker, R., Gasson, J., Ogawa, M., and Koeffler, P. (1986) Recombinant human tumor necrosis factor induces production of granulocyte-macrophage colony-stimulating factor mRNA and protein from lung fibroblast and vascular endothelial cells in vivo. Nature, 323:79-82.

Nimer, S.D., Gates, M.J., Koeffler, H.P., and Gasson, J.C. (1989) Multiple mechanisms control the expression of granulocyte-macrophage colony-stimulating factor by human fibroblasts. J. Immunol., 143(7):2374-2377.

Ozturk, S.S., and Palsson, B.O. (1990) Chemical decomposition of glutamine in cell culture media: Effect of media type, $\mathrm{pH}$, and serum concentration. Biotechnol. Prog., 6:121-128.

Patt, H.M., Maloney, M.A., and Flannery, M.L. (1982) Hematopoietic microenvironment transfer by stroma fibroblast derived from bone marrow varying in cellularity. Exp. Hematol., 10: 738-742.

Rich, I.N., and Kubanek, B. (1982) The effect of reduced oxygen tension on colony formation of erythropoietic cells in vitro. Br. J. Haematol., 52:579-588.

Shannon, M.F., Gamble, J.R., and Vadas, M.A. (1988) Nuclear proteins interacting with the promoter region of the human granulocyte/macrophage colony-stimulating factor gene. Proc. Natl. Acad. Sci. U.S.A., 85:674-678.

Shaw, G., and Kamen, R. (1986) A conserved AU sequence from the $3^{\prime}$ untranslated region of GM-CSF mRNA mediate selective mRNA degradation. Cell, 46(5):659-667.

Slovick, F.T., Abboud, C.N., Brennan, J.K., and Lichtman, M.A. (1984) Survival of granulocytic progenitors in the nonadherent and adherent compartments of human long-term marrow cultures. Exp. Hematol., 12:327-338.

Thorens, B., Mermod, J.J., and Vassalli, P. (1987) Phagocytosis and inflammatory stimuli induce GM-CSF $\mathrm{mRNA}$ in macrophages through posttranslational regulation. Cell, 48:671-679.

Toogood, I.R.G., Dexter, T.M., Allen, T.B., Suda, T., and Lajtha, L.G. 
(1980) The development of a liquid culture system for the growth of human bone marrow. Leuk. Res., 4:449-461.

Verfaillie, C., Blakolmer, K., and McGlave, P. (1990) Purified primitive human hematopoietic progenitor cells with long-term in vitro repopulating capacity adhere selectively to irradiated bone marrow stroma. J. Exp. Med, 172:509-520.

Zucali, J.R., Dinarello, C.A., Oblon, D.J.,Gross, M.A., Anderson, L. and Weiner, R.S. (1986) Interleukin 1 stimulates fibroblasts to produce granulocyte-macrophage colony-stimulating activity and prostaglandin $\mathrm{E}_{2}$. J. Clin. Invest., 77:1857-1863.

Zucali, J.R., Broxmeyer, H.E., Dinarello, C.A., Gross, M.A., and Weiner, R.S. (1987) Regulation of early human hematopoietic (BFU-E and CFU-GEMM) progenitor cells in vitro by interleukin 1-induced fibroblast-conditioned medium. Blood, 69(1):33-37. 